\title{
Doctorale en postdoctorale opleiding nieuwe stijl
}

De accountantsopleiding aan de Rijksuniversiteit Limburg (RL)

Drs. E.H.J. Vaassen en Drs. R.J.M. Dassen

\section{Inleiding $^{1}$}

De Economische Faculteit van de Rijksuniversiteit Limburg is een relatief kleine, internationaal gerichte faculteit met ongeveer 300 medewerkers en ongeveer 2000 studenten. Dit zijn tevens de streefgetallen. Bij de start van de faculteit in 1984 was niet voorzien in een postdoctorale accountantsopleiding, doch de - nog korte - geschiedenis heeft uitgewezen dat deze opleiding in een behoefte voorziet Elk opleidingstraject aan de RL wordt in principe gekenmerkt door de probleemgestuurde aanpak en de daaraan inherente kleinschaligheid. Onderwijs vindt plaats in kleine groepjes van 10-13 studenten die onder begeleiding van een (al dan niet inhoudsdeskundige) tutor bepaalde - rondom thema's gegroepeerde - problemen als vertrekpunt voor hun studieactiviteiten nemen. De Postdoctorale Accountantsopleiding is hierop geen uitzondering: ook hier staan de probleemgestuurde aanpak en de kleinschaligheid hoog in het vaandel.

De kleinschaligheid manifesteert zich ook in het aantal studenten dat opteert voor de Postdoctorale Accountantsopleiding en het daaraan voorafgaande Doctoraaltraject Berichtgeving: momenteel is de instroom in het derde jaar van de doctoraalfase stabiel op ongeveer 70 studenten. Daarvan valt gedurende het traject ongeveer $40 \%$ af (mede doordat het programma als zwaar wordt ervaren), waardoor jaarlijks ongeveer 40 RL-studenten kunnen instromen in de Postdoctorale Accountantsopleiding. ${ }^{2}$ Daarnaast stromen tot heden jaarlijks nog maximaal 20 NIVRA studenten in. In totaal start de Postdoctorale Accountantsopleiding dan jaarlijks met 60 studenten. Verdere uitbouw wordt strategisch en didactisch niet wenselijk geacht.

In dit artikel wordt enerzijds een beeld geschetst van de organisatorische inbedding van de Postdoctorale Accountantsopleiding en het Doctoraaltraject Berichtgeving binnen de Economische faculteit van de $R L$, en wordt anderzijds een visie ontvouwd op de toekomst van de accountantsopleiding in Nederland, een visie die al gedeeltelijk is te herkennen in de accountantsopleiding aan de RL.

\section{Traject Berichtgeving}

De accountantsopleiding is verbonden aan de Sectie Berichtgeving ${ }^{3}$ Met name de relatie met de berichtgevingsvakken: Financiële Informatiesystemen (FIS; Boekhouden in ruime zin), Externe Berichtgeving (EB), Internationale Externe Berichtgeving, Interne Berichtgeving (IB) en Bestuurlijke Informatieverzorging/Administratieve Organisatie (BIV/AO) is bepalend

Drs. E.H.J. Vaassen studeerde economie en accountancy aan de Rijksuniversiteit Limburg. Sinds 1988 verbonden aan (een rechtsvoorganger van) Deloitte \& Touche. Sinds 1990 is hij docent aan de Rijksuniversiteit Limburg en part-time werkzaam bij Deloitte \& Touche.

Drs. R.J.M. Dassen studeerde economie en accountancy aan de Rijksuniversiteit Limburg. Hij is als manager verbonden aan Deloitte \& Touche en als adjunct-directeur aan de Postdoctorale Accountantsopleiding aan de Rijksuniversiteit Limburg. 


\section{MAB}

geweest voor deze keuze. Internationaal zijn de vakken 'Financial Accounting' (vergelijkbaar met EB) en 'Management Accounting' (vergelijkbaar met IB) ingeburgerd. Het is aardig om te constateren dat een kernvak binnen de Nederlandse accountantsopleiding - namelijk BIVIAO - in geen van de ons omringende landen als zodanig wordt aangeboden. Veeleer loopt het vak BIV/AO als een rode draad door enkele andere vakken, zoals: 'Management Accounting', 'Accounting Information Systems', en 'Auditing'. Hiermee is meteen verklaard waarom aan de $R L$ het vak 'Informatiemanagement' zo sterk gekoppeld is aan BIV/AO. 'Informatiemanagement' houdt zich namelijk bezig met problemen van organisaties en informatietechnologie, informatieplanning, systeemontwikkeling en systeembeheer, problemen waar 'Accounting Information Systems' zich ook mee bezighoudt. Het vak 'Auditing' is enige jaren geleden vanuit de Postdoctorale Accountantsopleiding naar voren geschoven. Het betreft hier een vak dat studenten laat kennismaken met het beroep van accountant. Thema's hierin zijn: het ontstaan van het beroep, de betekenis in onze huidige economie, de verschijningsvormen, produkten en ontwikkelingen, en elementaire controlemethoden en -technieken.

Het Traject Berichtgeving is een studietraject dat gevolgd moet worden om te kunnen worden toegelaten tot de Postdoctorale Accountantsopleiding. ${ }^{4}$ Naast vorengenoemde vakken is binnen dit traject ruimte gereserveerd voor vakken als: 'Financieel Management', 'Financiële en Actuariële Wiskunde' (inclusief steekproeftoepassingen binnen de accountantscontrole), 'Fiscaal Recht' (ook internationaal) en 'Ondernemingsrecht'. Daarnaast is er een aantal vaardigheidstrainingen ontwikkeld dat eveneens onderdeel uitmaakt van het Traject Berichtgeving. Het betreft hier de verplichte vakken: 'Administratieve Organisatie en Schematechnieken', en 'Financiële Analyse en Cijferbeoordeling' en de keuzevakken (twee van de vier): 'Het Gebruik van de Microcomputer bij Financieel-Economische Beslissingscalcu- laties', 'Ontwerpen van een Expert Systeem ten behoeve van Bedrijfsdiagnose'. 'Ontwerpen van Financiële Informatiesystemen' en 'Communicatieve Vaardigheden in Accountancy'.

Los van het Traject Berichtgeving worden de keuzevakken: 'Hoofdlijnen BIVIAO' (voor bedrijfseconomen die zich niet verder willen specialiseren) en het engelstalige 'Accounting Information Systems' (voor Studenten Internationaal Management), verzorgd. Tevens worden de vakken: 'Informatietechnologie en Organisatiehervorming', 'Automatisering en Recht', en 'Informatie-economie' aangeboden voor geinteresseerden.

Het vak BIVIAO wordt, zoals hierboven blijkt, aangeboden in het Doctoraaltraject Berichtgeving. Dit leidt ertoe dat gedurende de doctoraalfase reeds deelgenomen kan worden aan het (nu nog) Landelijk Examen Administratieve Organisatie. Het slagen voor het Landelijk Examen is echter geheel losgekoppeld van het behalen van het doctoraalexamen. We leiden immers primair bedrijfseconomen op en géén AO-specialisten. Ten behoeve van het Landelijk Examen $\mathrm{AO}$ wordt derhalve een aparte training aangeboden die feitelijk deel uitmaakt van de Postdoctorale Accountantsopleiding, doch die gedurende de doctoraalfase gedoceerd wordt: de training 'Cases in $\mathrm{AO}^{\prime}$ '. Vanwege het postdoctorale karakter van het Landelijk Examen $\mathrm{AO}$ en de daaraan voorafgaande examentraining dienen studenten cursus- en examengeld te betalen

Binnen het Traject Berichtgeving is er een vaste staf, bestaande uit (bijna) fulltimers. Universitaire medewerkers - waaronder RA's dienen in principe gepromoveerd te zijn. Aan deze eis kan thans in Maastricht in voldoende mate worden voldaan c.q. zal binnen afzienbare tijd kunnen worden voldaan (hier heeft in het verleden gegolden: 'nood breekt wet') Daarnaast is er een groot aantal parttime vakdocenten die voornamelijk werkzaam zijn in de accountantspraktijk. Met name bij het vakgebied BIV/AO - inclusief 'Informatiemanagement' en 'Auditing' - houdt de fulltime staf zich 
voornamelijk bezig met onderzoek, onderwijsplanning, onderwijsprogrammering en onderwijscoördinatie, en de parttime staf met het begeleiden van onderwijsgroepen, workshops, scripties en dergelijke. Bij de juridische vakken wordt gebruik gemaakt van de diensten van de Faculteit der Rechtsgeleerdheid.

Ten behoeve van afgestudeerde HEAO-ers BE of $R A$ is aan de $R L$ een doorstroomprogramma ontwikkeld. Dit doorstroomprogramma is in september 1994 gestart. Middels dit programma kunnen HEAO-ers BE binnen 2 jaar het doctoraalexamen Bedrijfseconomie behalen. Indien desbetreffende studenten het Traject Berichtgeving met succes afsluiten kunnen zij worden toegelaten tot de Postdoctorale Opleiding Accountancy. Daarenboven geldt voor HEAO-ers RA nog een aantal vrijstellingen binnen het Traject Berichtgeving. Concreet betekent dit dat zij géén studieduurverkorting krijgen, doch dat het programma iets minder zwaar is. Aldus kunnen HEAO-ers BE of RA binnen 3 jaar na hun HEAO-examen zowel de drs-titel als de RA-titel ${ }^{5}$ behalen.

Goed onderwijs gaat gepaard met goed wetenschappelijk onderzoek en andersom. Aan de sectie Berichtgeving is het onderzoeksinstituut MARC (Maastricht Accounting and Auditing Research Center) verbonden. Het MARC houdt zich bezig met contract-onderzoek, organiseert cursussen voor jonge onderzoekers - veelal pas afgestudeerde danwel bijna RA's of RC's - en organiseert symposia. Aan het MARC zijn gerenommeerde onderzoekers met klinkende namen als Mock, Zeff en Merchant verbonden. Daarnaast worden regelmatig gastonderzoekers voor enkele weken of maanden per jaar ontvangen die hun verblijf aan de $\mathrm{RL}$ gebruiken om onderzoeksprojecten met RLmedewerkers op te zetten, promovendi - op de binnen het MARC onderscheiden onderzoeksterreinen: 'Financial Accounting', 'Management Accounting' en 'Auditing' - te begeleiden en onderwijs te verzorgen. Momenteel zijn er tien - pas ( $<5$ jaar) afgestudeerde danwel bijna afgestudeerde - RA's bezig met een promotie-onderzoek. Van deze tien werkt een aantal in de praktijk. De eerste promoties worden nog in 1994 verwacht. Feit is, dat de accountantsopleiding een positieve uitstraling ondervindt van de manier waarop aan wetenschappelijk onderzoek binnen de sectie Berichtgeving wordt vormgegeven.

\section{Postdoctorale Accountantsopleiding}

Afgestudeerde bedrijfseconomen, fiscaal economen of bedrijfskundigen met het juiste vakkenpakket (het Traject Berichtgeving aan de $R L$ of anderszins, wat per specifiek geval beoordeeld moet worden) die het Schriftelijk Landelijk Examen Administratieve Organisatie met succes hebben afgerond kunnen in september van elk jaar aan de Postdoctorale Opleiding Accountancy (PDOA) beginnen. Voorwaardelijke toelating is mogelijk indien het Landelijk Examen AO (schriftelijk, mondeling, danwel allebei) nog niet behaald is maar bij de eerstvolgende mogelijkheid wordt deelgenomen aan dat examen. Eventuele deficiënties kunnen via contractonderwijs aan de RL. eventueel aangevuld met cursussen aan de Open Universiteit, weggewerkt worden.

De Postdoctorale Accountantsopleiding begint met een Integratieblok Administratieve Organisatie/Leer van de Accountantscontrole (LAC). In dit blok wordt de samenhang tussen AO en LAC middels literatuur- en casestudies duidelijk gemaakt. Tevens komen aspecten van EDP-auditing aan bod in dit blok. De hoofdmoot van de PDOA wordt gevormd door het vak Leer van de Accountantscontrole, aangevuld met een klein stuk Externe Berichtgeving.

De wijze van toetsing van het vak $L A C$ is ietwat afwijkend van die van de andere universiteiten met een postdoctorale opleiding tot Registeraccountant. Examinering vindt voor een groot deel decentraal en gespreid gedurende de opleiding plaats. Dit heeft als voordeel dat er een veelheid van toetsinstrumenten toegepast kan worden, wat tegemoet komt aan de veel gehoorde kritiek dat de examens in de accountantsopleiding niet meten wat ze 
moeten meten, namelijk: is/wordt de kandidaat een goede accountant? Door de ruime mogelijkheden en het relatieve belang van de eigen toetsing voor de cijferbepaling, zijn ook de mogelijkheden voor onderwijsvernieuwing sterk toegenomen. In het studiejaar 1993/1994 is in het verlengde hiervan een aantal belangrijke innovaties doorgevoerd, zoals

- het reeds genoemde Integratieblok $A O / L A C$

- een drietal 'special'-blokken waarin op vrijdag en zaterdag aandacht wordt besteed aan achtereenvolgens international auditing, interne (inclusief operational) en overheids-audits, alsmede een geintegreerde EDP-audit casus; en

- presentatie- en communicatievaardigheden die in het verlengde, doch onafhankelijk van het doctoraalvak 'Communicatieve Vaardigheden in Accountancy' worden aangeboden.

Een belangrijke didactische component in de opleiding aan de $R L$ is de huidige combinatie van RL-cursisten en NIVRA-cursisten in de onderwijsgroepen. Door integratie van deze cursisten met een geheel verschillende achtergrond wordt in de (ook hier: kleinschalige) onderwijsgroepen van maximaal 12 studenten, onder intensieve begeleiding van twee docenten per groep. een optimale mix van theoretische en praktische kennis gecreëerd, die door beide groepen studenten als waardevol wordt ervaren.

De Postdoctorale Opleiding Accountancy aan de $R L$ kan in principe binnen één jaar worden afgerond. Dit is echter niet voor alle studenten weggelegd. Gegeven het feit dat accountancy-studenten na het behalen van hun doctoraalexamen bij een accountantskantoor, bij een interne accountantsdienst of in een controllers-achtige functie gaan werken en aldaar veelal tot de conclusie komen dat ze nog een niet te veronachtzamen praktijkleerproces moeten doorlopen bovenop hun postdoctoraal leerproces, lijkt het realistischer een termijn van anderhalf jaar aan te houden

Voor de personele bezetting van de Postdoctorale Opleiding wordt - evenals bij BIV/AO - een beroep gedaan op parttimers. Voor onderwijsprogrammering en opleidingscoördinatie beschikt de Postdoctorale Opleiding over twee parttimers met een ruimere aanstelling, terwijl voor de bemanning van de onderwijsgroepen een beroep wordt gedaan op RA's met een beperktere aanstelling die werkzaam zijn bij accountantskantoren, het bedrijfsleven of de overheid.

\section{Toekomst}

Mede met het oog op de implicaties van de veranderde wetgeving op het gebied van de accountantsexamens, is een aantal principiële beslissingen genomen aangaande het curriculum, de aandachtspunten en wenselijk geachte ontwikkelingen binnen de accountantsopleiding.

Ten eerste, er wordt vooralsnog niet gestreefd naar een opleiding waarin Accountancy geheel in de doctoraalfase geintegreerd wordt. waardoor er in de toekomst accountants op de markt komen die hun opleiding geheel in een doctoraaltraject hebben afgerond (het zogenoemde doctoraal accountancy). De RL acht de accountantsopleiding te zeer beroepsgericht om zonder meer in een academische opleiding geintegreerd te kunnen worden. Bovendien is de combinatie van studie en werken - ook al is het maar één jaar - een wezenlijk onderdeel van de vorming van accountants, hetgeen ook in de op handen zijnde stageverplichting wordt weerspiegeld. Het huidige doctorale en post-doctorale curriculum aan de RL is voorts reeds afgestemd op de onderwijssituatie die als gevolg van deze stageverplichting gaat ontstaan. Overigens schat de $R L$ de rol van de universiteit binnen het stagetraject als zeer bescheiden in; de hoofdmoot van de invulling van het praktijkgedeelte zal naar onze mening door de kantoren worden verzorgd.

Ten tweede, het curriculum zal generalistisch van aard blijven. Dit betekent dat specialisa- 
ties zoals: EDP-Audit, Milieu-Audit (c.q. -Accounting), Operational Audit e.d. weliswaar aandacht in het curriculum krijgen, maar dat er geen aparte studierichtingen voor worden ontwikkeld. De schaarse beschikbaarheid van goede leerboeken en het nagenoeg ontbreken van fundamenteel wetenschappelijk onderzoek op deze terreinen liggen aan deze beleidslijn ten grondslag. Bovendien zijn de financiële risico's te groot, temeer als men bedenkt dat andere universiteiten met een accountantsopleiding al in deze gaten in de markt zijn gesprongen. Wel wil de RL haar geografische ligging 'uitbuiten' door een aantal cursussen op het terrein van de internationale accountancy te organiseren. Door het MARC is reeds een onderzoek naar de behoefte aan dit type cursussen uitgevoerd. De resultaten van dit onderzoek zijn hoopgevend

Ten derde, contacten met afgestudeerde RLaccountants vragen de nodige aandacht. Zij kunnen informatie geven over onderdelen van de opleiding die veranderd dan wel aangepast moeten worden. Bovendien wordt ernaar gestreefd de nieuw te benoemen docenten uit het bestand van RL-afgestudeerden te putten, dit om de specifieke RL-filosofie zo efficiënt mogelijk te kunnen continueren, ook in de postdoctorale opleidingen. Om de contacten met afgestudeerden te bestendigen is in $1993 \mathrm{ge}$ start met het organiseren van een terugkommiddag waarin RL-accountants (studenten, maar ook docenten) enerzijds deelnemen aan een mini-symposium rondom een bepaald thema, en anderzijds deelnemen aan een sociaal programma. Op basis van een enquête, gehouden tijdens deze terugkommiddag, is besloten in het kader van de permanente educatie een jaarlijks terugkerende driedaagse cursus te organiseren (drie vrijdagen in september/oktober). De eerste cursus zal worden opgezet rondom enkele thema's uit de 'Management Accounting'. Het is de bedoeling een cursuspakket te ontwikkelen, waaruit de afgestudeerden een keuze kunnen maken. Dit pakket krijgt een bedrijfskundige inkleuring.
Ten vierde, internationalisering houdt meer in dan het ontwerpen van cursussen waarbij in de titel het woord 'internationaal' is opgenomen. Aan de RL wordt gestreefd naar meer inbreng door buitenlandse docenten. Voorts worden studenten gestimuleerd internationale uitwisselingsprogramma's te volgen. De hoop is dat ook studenten uit het Traject Berichtgeving - ondanks de zwaarte van het programma - hieraan meer zullen gaan deelnemen. Internationale stages behoren daar ook toe. De verslechterde arbeidsmarktomstandigheden voor accountants vormen overigens een onverwachte steun in de rug voor deze internationale stageprogramma's. Alsdan is profilering mogelijk door iets extra's te doen tijdens de studie, internationale uitwisseling en stages passen daar prima in.

\section{Tenslotte}

Universitaire accountantsopleidingen moeten zich richten op hun primaire taak, het verzorgen van onderwijs in de basisvakken waarvan accountants in spe kennis moeten hebben alvorens ze in de praktijk gaan werken, met andere woorden: het opleiden van breed inzetbare generalisten. In de praktijk kan dan blijken dat deze generalisten op bepaalde terreinen bijscholing nodig hebben. Dit is iets wat door de accountantskantoren over het algemeen redelijk goed wordt opgevangen. Naar onze mening is dit de enig juiste invalshoek van een universitaire accountantsopleiding. Specifiek voor de RL geldt dat internationalisering, kleinschaligheid (ingegeven door het probleemgestuurd onderwijs aan de $R L$ ), intensieve begeleiding en de stimulering van sociale vaardigheden de hoogste prioriteit blijven houden in het streven naar handhaving en eventueel een (beperkte) uitbouw van de marktpositie. Daarenboven vraagt het wetenschappelijk onderzoek - vooral ook ter ondersteuning van het onderwijs - veel aandacht. 


\section{Literatuur}

Maastricht Accounting and Auditing Research Center (1993), Annual Report, Rijksuniversiteit Limburg, Maastricht.

Postdoctorale Opleiding tot Registeraccountant, (1993), Jaarverslag 1992/1993, Faculteit der Economische Wetenschappen, Rijksuniversiteit Limburg, Maastricht. Postdoctorale Opleiding tot Registercontroller, (1993), Jaarverslag 1989-1990-1991. Faculteit der Economische Wetenschappen, Rijksuniversiteit Limburg, Maastricht.

Studiegids Economie, Econometrie, Internationale Bedrijfskunde, (1993, 1994), Rijksuniversiteit Limburg, Maastricht.

\section{Noten}

$1 \mathrm{Bij}$ het schrijven van dit artikel is onder andere gebruik gemaakt van een notitie van Prof. A. Beek RA inzake de accountantsopleiding aan de $R L$.

2 Overigens is een aan populariteit winnend alternatief voor de Postdoctorale Accountantsopleiding de Postdoctorale Controllersopleiding. Vermoedelijk zal deze opleiding aan de $R \mathrm{~L}$ een te verwachten teruggang in de Postdoctorale Accountantsopleiding enigermate kunnen compenseren. 3 Evenals de Postdoctorale Controllersopleiding en, vanaf 1995, Fiscale Economie.

4 De aansluiting met de Postdoctorale Controllersopleiding is gegarandeerd indien binnen dit traject Management Control' in plaats van 'Auditing' en 'Interne Berichtgeving en Organisatie' in plaats van 'Externe Berichtgeving II' wordt gevolgd.

5 De huidige Postdoctorale Controllersopleiding, met de titel $R C$, duurt $2 \frac{1}{2}$ jaar. 